\title{
Exerting Pressure in Strategic Negotiations
}

\author{
Fenglin $\mathrm{An}^{1,{ }^{*}, a, \dagger}$, Jiarui Liang ${ }^{2, *, b, \dagger}$, Guangchang $\mathrm{Lu}^{3,{ }^{3}, \mathrm{c}, \uparrow}$ \\ ${ }^{1}$ University of Washington-Seattle, Seattle, 98195, U.S, \\ ${ }^{2}$ Xi' an Jiaotong-Liverpool University, Suzhou, 215000, China, \\ ${ }^{3}$ Faculty of Social Science, Western University, London, Ontario, N6A3k7, Canada, \\ *Corresponding author.Email: ${ }^{*}$ fenglin.an@qq.com, ${ }^{\text {2}} 290903963 @ q q . c o m,{ }^{c}$ glu48@uwo.ca \\ These authors contributed equally.
}

\begin{abstract}
As one of the most powerful methods in strategic negotiation, imposing pressure has been recognized and applied to a great extent and achieved success in a number of negotiation cases. The purpose of this article is to elaborate on the pressure in negotiation by summarizing the conclusions of previous studies. Whilst several journal articles have discussed how to exert pressure in negotiations, a gap of comprehensive understanding still exists because of lacking a presentation from multifold perspectives. This work would thereby present a general review of different pressure applications in negotiations, including threats, time pressure, ultimatums, and information pressure. It is shown that pressure would be helpful and assistant to negotiation when applied properly. Meanwhile, a list of pros and cons of negotiation pressure is finally given, which should be paid attention to when applying such a tactic in negotiation scenarios.
\end{abstract}

Keywords: Strategic negotiation, Threat, Ultimatums, Time pressure, Information pressure.

\section{INTRODUCTION}

Over the centuries, human negotiation behaviors, rituals, and methods have continuously evolved to adapt to the changes in the surrounding social, biological, political, cultural, and economic environment. These behaviors are no different from all other manifestations of human biology, psychology, and language and are bound by the basic principles of evolution [1]. It can be said that the human brain itself has expanded over the centuries, partly because of the increasing volume of the negotiation process. Some physical anthropologists speculate that this change is not so much a need for stronger reasoning ability but the need to manage and deal with increasingly complex social and political affairs and deal with those interactions [1].

Specifically, as people live closer together in larger and denser cities, they need to detect and protect themselves from the deception and potential threats of others and then adopt similar strategies in their own transactions. Although humans and other species may be cruel to perceived enemies, they also often show sympathy and tolerance for those who cannot contribute [1]. Those who dominate the culture often give "lessors" some space to negotiate their existence. Thus, it can be said that whilst humans are inherently aggressive, they simultaneously also have a cooperative instinct to alleviate this aggressiveness. For instance, wars, though essentially conflicting, would always trigger negotiations to re-stabilize "peace."

When disputes arise between a business and personal relationships, it is easy to avoid conflicts to save the relationship. Nevertheless, it is not always possible to turn tense disputes into productive negotiations and maintain strong relationships. In these situations, negotiation skills are crucial to achieve the negotiation objectives and reach a win-win situation.

In this article, the negotiating pressure techniques are introduced to help maintain the power while ensuring the objectives can be accomplished. The negotiation pressure, as per definition, means that during business negotiations, when two parties have differences of opinions on the discussed issues, one party takes certain methods or actions to force the other party to act according to its wishes; otherwise, it will take actions to cause a result that is not conducive to the other party [2].

In this article, three techniques of pressure-based negotiation are introduced, including general threats strategy, time pressure, and information pressure methods. 
In the negotiation process, the party with more information is often the active party. Because information is power, the more you know about the opponent, the better your chances of winning. The more you know about your opponent, the better you can apply pressure; on the contrary, the less you know about your opponent, the more pressure you will face to negotiate.

\section{THREAT AS A GENERAL NEGOTIATION TECHNIQUE}

Negotiation threat, in general, means that during the negotiation process, when the two negotiating parties have differences of opinion on the discussed issues, one party may force the other party to act according to its own wishes. Otherwise, it will cause a result that is not conducive to the other party and is threatened [2].

Previous studies reveal that people consider their counterparts more favorably when they impose a certain level of pressure, which can be explained that pressure giving can manifest the responsibility of the other part. That being said, in many situations, the threats, in general, would facilitate the cooperation level [3].

An appropriately implemented threat would set out to meet the interests of both sides. Thus, beforehand, it is necessary to think about whether the selected threat will truly assist in achieving the goals; otherwise, some counterreaction may also be produced [3]. Therefore, the sections below delineated some considerations that need to be taken into when imposing threats.

To evaluate whether the threats are suitable or not, to begin with, it is imperative to appraise that whether the threats are based on reasoning rather than emotion. Good business negotiators should control their emotions and make plans before imposing any threats. For instance, if the mood of anger, such a threat should never be implemented [4]. According to extant psychological studies, it is found that the emotion of anger would have negative impacts on effective information understanding, leading to a riskier decision-making process [3].

When confirming that the threats are made based on a rational premise, it is crucial to further analyze the potential influences generated. As previous studies discussed, threats often provoke counter-threats and revenge from the counterpart [2]. As a result, before putting forward a certain threat, an all-around analysis should be comprehensively assessed to understand what are any possible consequences that you may encounter in the following negotiation process.

Finally, considering that the ultimate goal of negotiation is to fulfill and maximize the interests and benefits of your own, the treats should be conducted as a motivator rather than a punishment [3]. At the end of the day, threats should also be a facilitator to enhance your long-term relationship with the other side. Therefore, a trade-off between aggressive and mild threats tactics should be assessed [3].

\section{TIME PRESSURE}

The definition of time pressure can be stated as psychological stress that occurs when a person has less time available than is necessary to complete a task or obtain a result [5]. More specifically, time pressure refers to the use of limited time to achieve your advantage. What's more, if you know that other negotiators want (or need) to complete the transaction, you may have the opportunity to follow your own agenda [5].

Using time pressure is a tried-and-tested strategy that can gain the upper hand in high-pressure situations. In general, as stated in a previous study, an adequate time pressure, at low levels, produced outcomes that tend to be positive. It seems that if time pressure could be used appropriately in negotiation, it may bring numerous benefits to a certain extent [6].

Negotiation activities often have a certain time limit. When the negotiation is approaching the deadline, it seems that negotiators may face the pressure of time and become more flexible and easier to make concessions. It follows that the time limit makes sense when we pay attention to time pressure in negotiation [6].

The price of purchasing fruit, for example, is generally lower when the vendor is ready to close the stall. Vendors may be more eager to sell fruit and willing to finish the day's sale early. Sellers and consumers would be more likely to compromise with each other, and the price would be lower then.

Thus, when an advantage exists in negotiation or the situation is not urgent to make decisions, it is suggested to set a deadline for negotiation, bringing psychological pressure to the opposite side [7]. To be more specific, setting deadlines for the other party and clearly telling them how far the negotiation should go within the specified time. Otherwise, the negotiation would be canceled or the terms would not be as favorable as they are now. These tactics can exert certain time pressure on the other side, conducive to promoting the negotiation [7].

However, if the current situation is unfavorable and there is a time limit, it would be better to minimize the drawbacks that could be faced under time pressure and avoid telling the bottom line of time [7]. If the other side knows the time limit, it would be possible to lose the initiative. For example, in the case of oil rights, CPC faced the pressure to finish the deal soon, and if it failed to end the negotiation in time, CPC might face great trouble in future development if the other side got this information and use their advantage to interfere, such as 
deliberately prolonging the time and not ending the negotiation. This may put the company in a passive position in the negotiation, and CPC would be forced to accept their price or conditions. Overall, avoiding exposing the bottom line would bring benefits and may prevent other companies from putting time pressure on us [7].

In addition, timing is also important in negotiation, and the perfect timing of applying pressure may be different for different kinds of products [7]. For example, according to previous research, there is a decision that two products with different qualities should be released simultaneously or in sequence. If both products are put on sale at the same time, it is obvious that the demand for high-quality goods will be greatly reduced. But if they are rolled out one after another, then the benefits of low-end products will be reduced or be received much later than expected.

Time pressure would be faced when dealing with decisions on releasing timing. It would be important to balance the profits and project time-to-benefit [8]. It is stated that when the customers seem to be more impatient than the seller, the sequential introduction would be better than the simultaneous introduction [8]. However, sequential selling would be unsuitable in the situation where sellers are unable to make a promise, in which case, there would be a lacking product design and would be of little help to mitigate cannibalism. In general, it is suggested to choose the best time to sell, depending on different situations, and sellers should better consider different conditions before deciding the timing.

In conclusion, time can sometimes react as a key point in negotiation, and negotiators should use the time pressure and deal with it properly in business negotiation scenarios.

\section{ULTIMATUM AS AN EFFECTIVE PRESSURE MEANS}

An ultimatum is a special form of time pressure, which is to give a deadline or a final condition for the opponent. If they did not accept it, negotiations would be terminated [8]. Ultimatums are also an effective way that is the most common to exert negotiating pressure. It can often get the other side to make quick concessions because it breaks the deadlock between the two sides, puts pressure on the other side, and asks the opponent to make concessions under challenging circumstances. This strategy is putting intense pressure on the other side to make concessions under challenging situations. This kind of concessions will increase existing benefits and has a successful negotiation [9].

To be more specific, an ultimatum is to give the other side a deadline and conditions for a final reply if the other side does not agree to quit the negotiation.
Although ultimatums are helpful in negotiations, the final effect depends on the negotiator's behavior inherent. If the negotiator prefers to collaborate, ultimatums will increase the possibility of reaching an agreement and promoting cooperation.

In contrast, in the direction of the negotiator is competition, negotiation will fail [10]. Also, if too much pressure is put on the opponent and totally breaks their original plans, their initiative can be harmed essentially. Although ultimatums are usually efficient, it may not always be effective [10]. Thus, whether to apply such a strategy should be considered very carefully.

\section{INFORMATION PRESSURE}

As per definition, we are trying to get more information about the opponent will generate information pressure. In other words, information is the basis for analyzing the real benefits and costs [1]. In the negotiation process, the party that has more information usually has a higher competitive advantage. In this case, information turns into a sort of bargaining power, and the more information obtained about the other side, the better chances of winning.

In the case of business negotiation, information includes any related data with respect to the counter party's decision-making process, strategies formulation, and underlying motivations to conduct the negotiation [11]. For example, suppose the company can know to what level the opponent's intention of cooperation is before the start of the negotiation. In that case, they can understand the opponent's bottom line and accordingly draft some strategies to, for example, get the lowest price.

In contrast, the less information is known about the opponent, the higher possibility of facing a disadvantaged position in the negotiation. It will make the company cannot find the best choice and get the utmost benefits. Consequently, information can be said as one of the essential assets for the negotiators [12].

While information is important in a negotiation, only a few people can analyze their opponents before they begin. To relieve the pressure of information in the negotiation, the negotiator must better understand the opponent, such as go out of their usual work environment to communicate or through their customers to learn information that will better understand the situation [11].

More than those traditional methods, searching information from different angles to enhance the diversity of information will increase the negotiation success rate [12]. In addition, try to get more information about the opponent also has the disadvantage. If such information is leaked, the opponent may decide to drop the negotiation, and some 
tricky legal issues such as the business secret violation may exist.

\section{CONCLUSION}

In sum, this article reveals several negotiation strategies, including threats in negotiation, time pressure, ultimatums, and information pressure. It can be concluded that threats in negotiation provide a basic assumption to harness the weaknesses of the negotiating parties to achieve the organizational goals. By giving the opponent a deadline or a final condition to break their original plans, time pressure and ultimatums are some of the most effective threats to get a better deal. Finally, getting more information will also help negotiators to obtain more bargaining power to enhance the possibility of winning the negotiation. In the actual business negotiation cases, all these strategies can be interrelated and applied together.

As for the results of applying such techniques, it could generate both positive and negative effects. First, when applied appropriately, pressure can be used to prompt the negotiator to adjust and balance the interests of both parties, and thus plays a positive role in promoting the success of the negotiation. Also, pressure can be used to enhance both parties to better involve in the negotiation process.

On the negative side, pressure can be a factor that produces huge differences and confrontations, leading to a deadlock or even a breakdown in the negotiations [2]. The long-term relationship between two parties can be essentially harmed. Meanwhile, for some types of negotiation, such as the negotiation with high-power distance, patience may be more critical than pressure. Thus, while exerting pressure can be conducive in most negotiation cases, the one-size-fits-all mindset would be wrong in the negotiation.

Nonetheless, in today's business world, pressure exists throughout the business negotiation process. The pace of growth of the company is constantly accelerating, and the transaction can be quickly concluded. Businessmen are doing everything possible to speed up negotiations. CEOs and other executives are under tremendous pressure to complete complex contracts through high-risk negotiations. One tiny mistake can cause millions of dollars in losses. In such a context, pressure, in most cases, would generally play a constructive role, even though some people or business cases can be potentially broken down if the pressure is overloaded. As discussed in this study, only in a way that the pressure imposing is strategically designed can the final results be constructive.

As for the implication for future studies, it is suggested that pertinent business cases can be further investigated to find out some best practices and rules of thumb of the applying threats and pressure into the business negotiation field.

\section{REFERENCES}

[1] Furmston, M. (1995). Threats, pressure and tough negotiation.

[2] White, J. B., Tynan, R., Galinsky, A. D., \& Thompson, L. (2004). Face threat sensitivity in negotiation: roadblock to agreement and joint gain. Organizational Behavior and Human Decision Processes, 94(2), 102-124.

[3] Haddock, D. D. (2003). Force, Threat, Negotiation: The Private Enforcement of Rights.

[4] Stuhlmacher, A. F., Gillespie, T. L., \& Champagne, M. V. (1998). The impact of time pressure in negotiation: a meta-analysis. International Journal of Conflict Management, 9(2), 97-116.

[5] Pruitt, D. G., \& Drews, J. L. (1969). The effect of time pressure, time elapsed, and the opponent's concession rate on behavior in negotiation. Journal of Experimental Social Psychology, 5(1), 43-60.

[6] Stuhlmacher, A. F., \& Champagne, M. V. (2000). The impact of time pressure and information on negotiation process and decisions. Group Decision and Negotiation, 9(6), 471-491.

[7] Humphrey, S. E., Ellis, A., Conlon, D. E., \& Tinsley, C. H. (2004). Understanding customer reactions to brokered ultimatums: applying negotiation and justice theory. Journal of Applied Psychology, 89(3), 466-82.

[8] Sistrunk, B. F. (1980). The effects of perceived ability and impartiality of mediators and time pressure on negotiation. The Journal of Conflict Resolution, 24(2), 311-327.

[9] Bo, A., Shen, Z., Miao, C., Tang, L., \& Cheng, D. (2006). Fuzzy Constraint Based Negotiation Under Time Pressure. IEEE International Conference on Industrial Informatics. IEEE.

[10] Rui, H. E. (2007). Pressure management in hostage crisis negotiation. Journal of Shanghai Police College.

[11] Mosterd, I., \& Rutte, C. G. (2000). Effects of time pressure and accountability to constituents on negotiation. International Journal of Conflict Management, 11(3), 227-247.

[12] Scholes, M. L., Wright, M., Westhead, P., Burrows, A., \& Bruining, H. (2007). Information sharing, price negotiation and management buy-outs of private family-owned firms. Small Business Economics, 29(3), 329-349. 